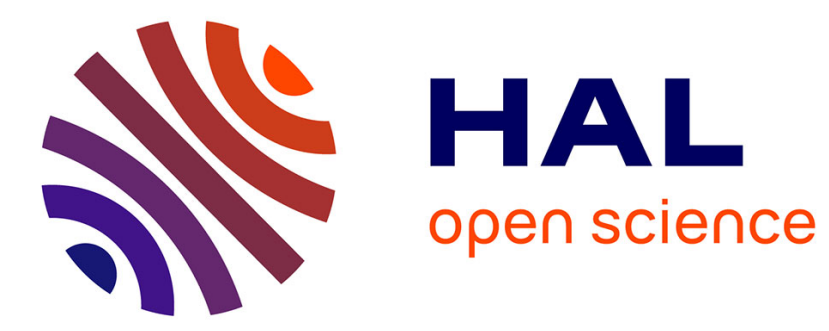

\title{
A Two-Dimensional Numerical Model to Analyze the Critical Velocity of High Speed Infrastructure
}

Riccardo Ferrara, Giovanni Leonardi, Franck Jourdan

\section{To cite this version:}

Riccardo Ferrara, Giovanni Leonardi, Franck Jourdan. A Two-Dimensional Numerical Model to Analyze the Critical Velocity of High Speed Infrastructure. Fourteenth International Conference on Civil, Structural and Environmental Engineering Computing, Aug 2013, Cagliari, Italy. 16 p., 10.4203/ccp.102.31 . hal-00873330

\section{HAL Id: hal-00873330 \\ https://hal.science/hal-00873330}

Submitted on 15 Oct 2013

HAL is a multi-disciplinary open access archive for the deposit and dissemination of scientific research documents, whether they are published or not. The documents may come from teaching and research institutions in France or abroad, or from public or private research centers.
L'archive ouverte pluridisciplinaire HAL, est destinée au dépôt et à la diffusion de documents scientifiques de niveau recherche, publiés ou non, émanant des établissements d'enseignement et de recherche français ou étrangers, des laboratoires publics ou privés. 


\title{
A Two-Dimensional Numerical Model to Analyze the Critical Velocity of High Speed Infrastructure
}

\author{
R. Ferrara* ${ }^{*} \ddagger$, G. Leonardi $\dagger$ and F. Jourdan $\ddagger$ \\ $\dagger$ DICEAM, University of Reggio Calabria, Italy \\ $\ddagger L M G C$, University Montpellier 2, France \\ Proceedings of the fourteenth international conference on civil, structural and environmental \\ engineering computing. \\ Cagliari, Sardinia, Italy 3-6 September 2013
}

\begin{abstract}
This paper illustrates the phenomenon of the critical speed in the range 100$300 \mathrm{~km} / \mathrm{h}$. A real explanation and a precise calculation of the critical speed seems to rest an unresolved problem in many cases. Some authors, analogous to "Mach effect", have attributed this phenomenon to the reaching the Rayleigh wave speed of substructure by trains. But this explanation can't be thorough in many cases because the Rayleigh wave speed is very high and the phenomenon happens even for lower speeds. This work shows an evident relationship between the receptance of the train/track coupling system and the so called sleeper-passing frequency. It is shown that the amplification of vibrations happens when the train speed causes the equivalence between the sleeper-passing frequency and the receptance of the train/track coupling system. This explanation seems to be definitively complete even if only a numeric validation is presented in the paper.
\end{abstract}

Keywords: critical speed, contact-force, modal analysis, track receptance.

\section{Introduction}

Field observations and measurements [1] have indicated a so called "Critical Train Speed" in the range $100-300 \mathrm{~km} \mathrm{~h}^{-1}$. At these conditions the moving of trains causes an increasing of vertical and lateral track vibrations. This

\footnotetext{
*Corresponding author. Email: riccardo85ferrara@gmail.com
} 
"mysterious" critical condition is described as the resonance between the moving train and the Rayleigh wave traveling in the soil embankment (analogous to the "Mach" effect caused by flying objects breaking through the sound barrier) [2]. Some authors [3,4] have affirmed that the problem is more complicated than a simply interaction with the Raylegh wave in the ground. They have treated the rail as beams on homogeneous half space. Basing on this assumption, it has been found that track should have two critical speeds, one equal to the Raylegh wave velocity of the ground, and another one, fairly close, controlled by the bending stiffness and the mass of the rail/embankment "beam" in addition to the ground properties [5]. Green's functions [2, 6, 7], wavelets [8], boundary and finite elements, even with the element net moving with the train [9], have been applied to try to predict track response to trains moving at speeds around the critical value [5]. Anyway a real explanation and a precise calculation of critical speed seems to rest an unresolved problem. Numerical models, and measurements show the amplification of contact force and displacement, but the physical explanations given to this phenomenon seem to be not satisfactory. In this paper a new approach and explanation is proposed.

\section{The 2D Numerical Model}

The numerical model used to study the vehicle/track vertical interaction is described in $[10,11,12]$. The dynamic computation considers mutual interactions in vehicle/track coupling system by means of a finite and discrete elements method. A draft of the vehicle/track model is shown in Figure 1. The vehicle is modeled by 7 bi-dimensional rigid elements corresponding to the body, the two boogies and the four wheels. A finite element discretization is used to model the rail. Considering insignificant the axial displacement, we discretized the rail with Timoshenko beam finite elements with two degrees of freedom: rotation and vertical displacement. Rail-pad is modeled as a combination of spring-damper couples without mass. In accordance with $[13,14,15,16,17]$ the sleeper is modeled as a discrete rigid element and the ballast is modeled as single blocks placed in correspondence of sleepers. A spring-damper couple, representing the elasticity and viscosity of the ballast blocks, connects them with sleeper-elements. Other spring-damper couples connect ballast blocks horizontally, allowing the transmission of vibration along the motion direction. Ballast stiffness is calculated according to [18]. To represent the behavior of background, a spring-damper couple is added over ballast blocks. The dynamic interaction between the wheelsets and the rail is accomplished by using the non-linear Hertzian model.

\section{The critical speed}

The phenomenon of critical speed has been revealed with the numerical model in two scenarios where two different types of vehicle are combined with the track system. Many simulations have been carried at constant vehicle speed; in each simulation the vehicle speed has been increased by $5 \mathrm{~km} \mathrm{~h}^{-1}$. The corrugation of the railway head has been fixed as a sinusoidal function with amplitude 0.025 


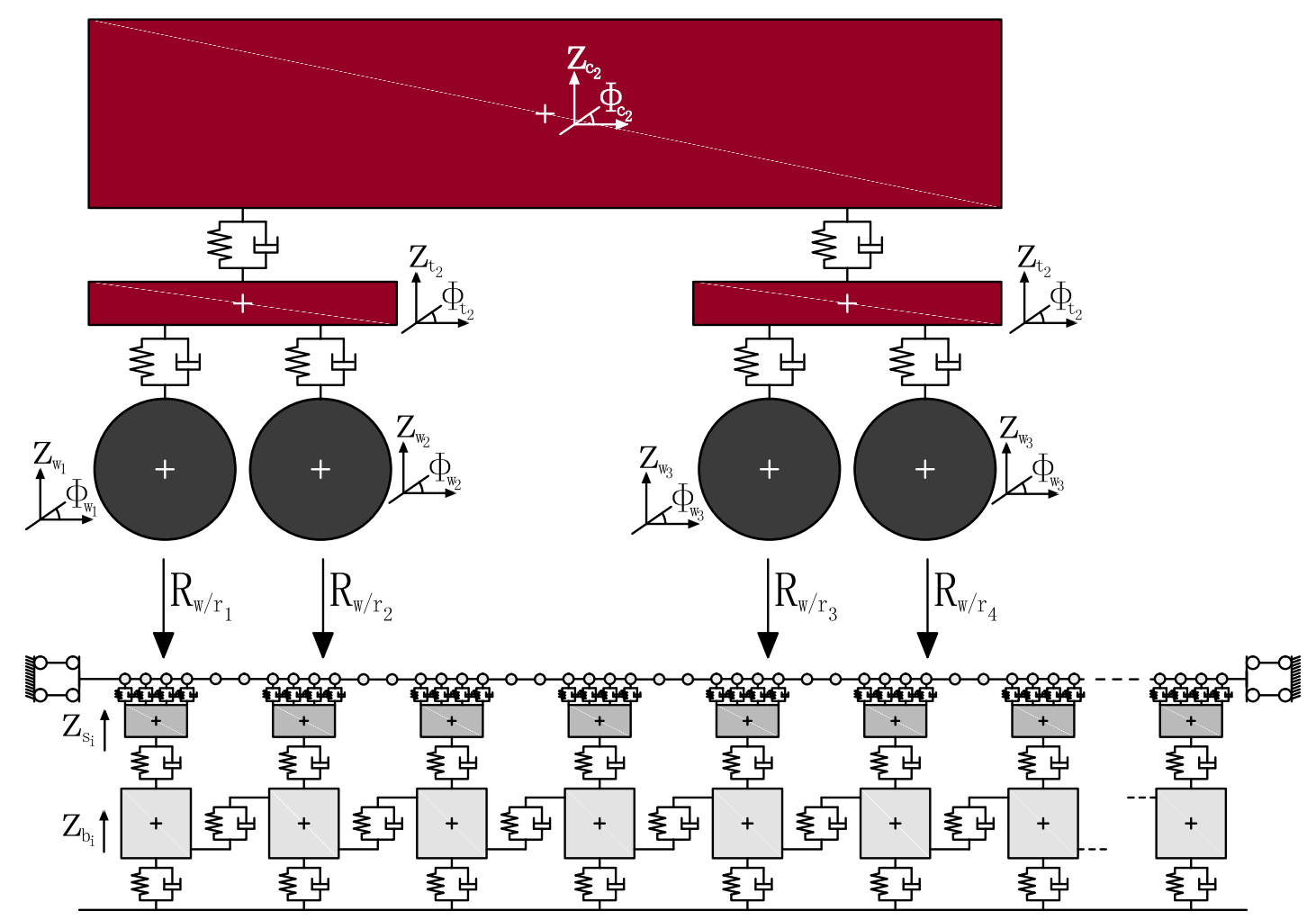

Figure 1: Draft of the vehicle/track model.

$\mathrm{mm}$ and wavelength $5 \mathrm{~mm}$. To appreciate the phenomenon of critical speed, two parameters have been checked during each simulation: the sleeper vertical displacement $z_{s l}$ and the dynamic amplification factor $\delta_{d y n}$ (the parameters are defined in Annex A). The results of the two scenarios are presented in the following paragraphs.

\subsection{The two scenarios studied}

In the first scenario the vehicle adopted is the ALN668 locomotive and the rail is a $60 \mathrm{E} 1$ type; the parameters for the vehicle and the track model are reported in table 1. In the second scenario studied, the vehicle used is the type 1 of the Manchester Benchmark [19] and the substructure parameters are the same of the previous scenario. The critical speed phenomenon results evident looking the dynamic amplification factor and the sleeper vertical displacement shown in figures 2 and 3. In the first scenario (figure 2) a critical speed is observed at 250 $\mathrm{km} \mathrm{h}^{-1}$. In the second scenario (figure 3) the critical speed results lower: 145 $\mathrm{km} \mathrm{h}^{-1}$. It can be noticed also that the critical speed range is $V_{c} \pm 50$ in the first scenario and $V_{c} \pm 25$ in the second one; maybe this interval is larger with the increasing of critical speed [12]. Focusing on figure 3(a), the behavior of the curve can be separated in five ranges. In the first range $40-120 \mathrm{~km} \mathrm{~h}^{-1}$ the tendency of the curve is an inverse proportion. This fact could be explained with a comparison to road infrastructure. It is well known how the dynamic modulus 


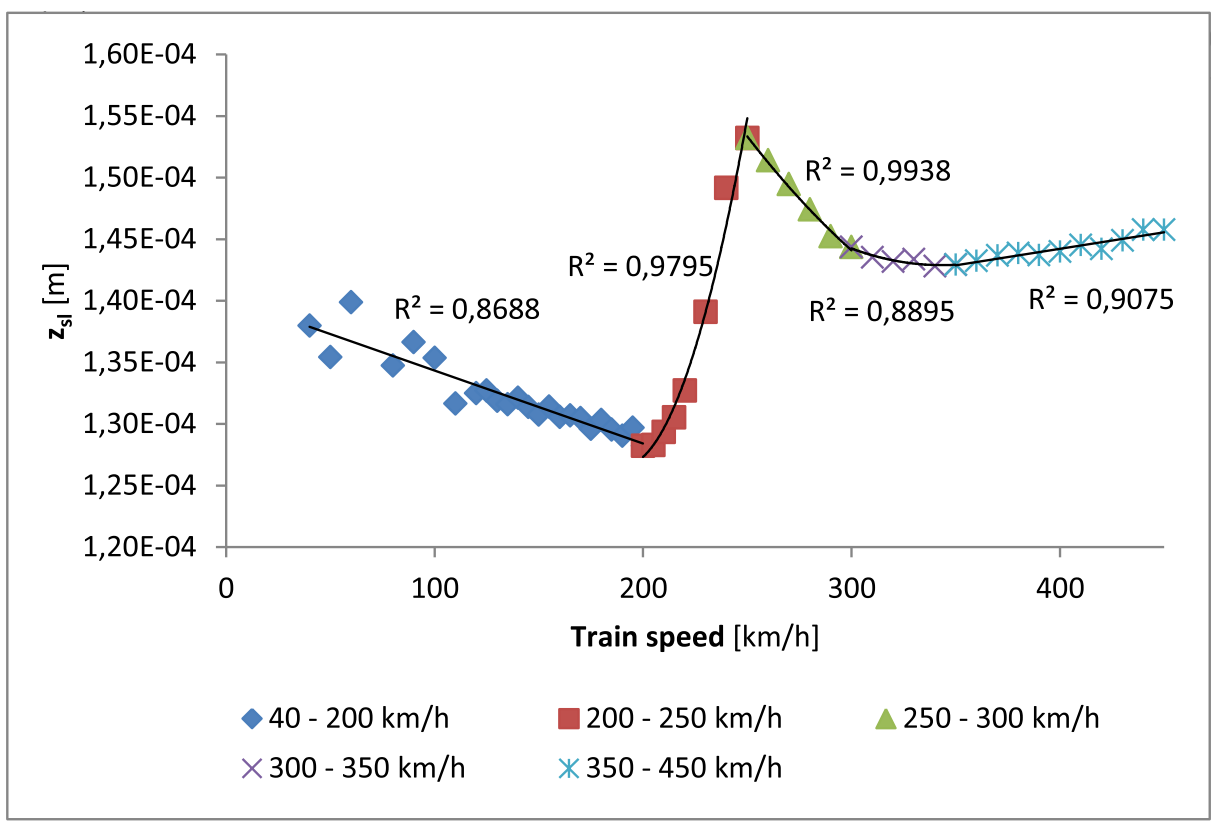

(a)

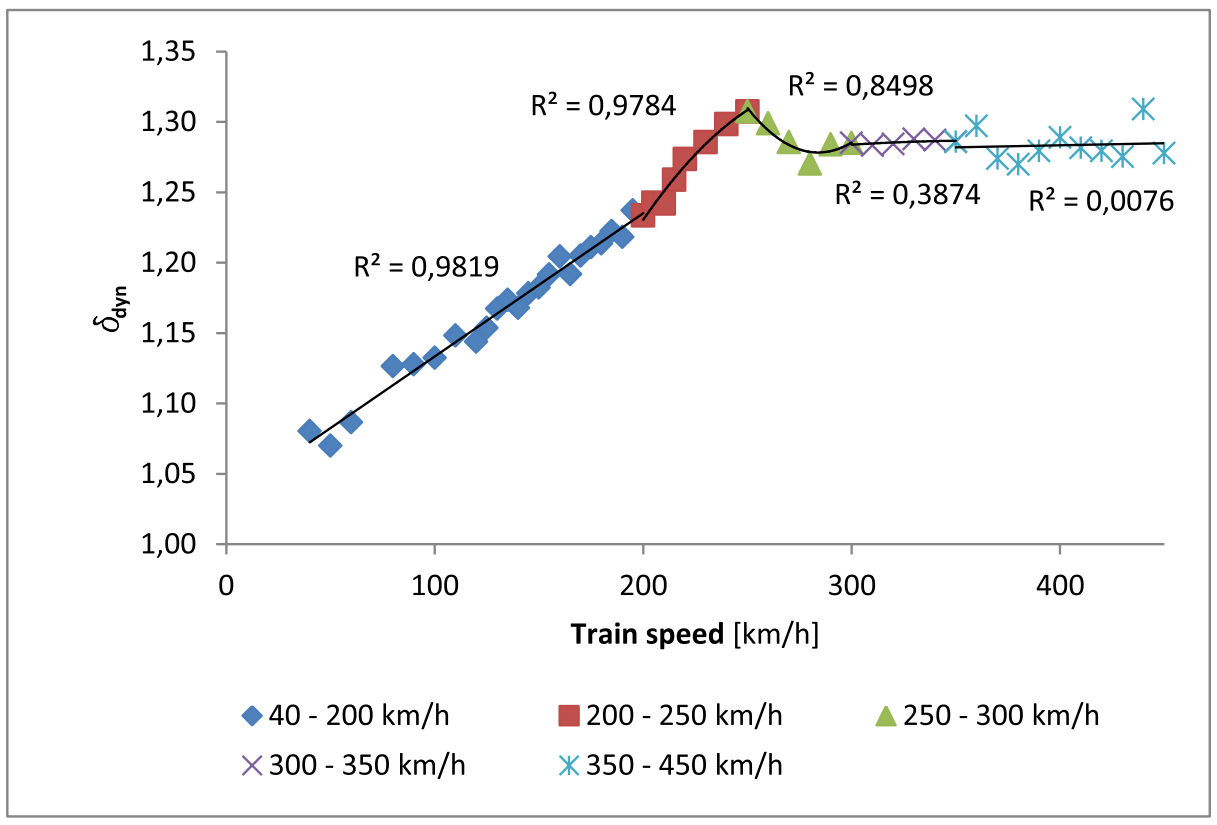

(b)

Figure 2: Scenario 1: (a) sleeper vertical displacement and (b) dynamic amplification factor in function of train speed

of many material is directly proportional to the frequency of excitation. This is the case for the road infrastructure. Indeed the slower vehicles, weight being equal, produce much rutting than faster vehicles. In the same way it can be affirmed that, for slow speeds, the equivalent complex modulus of substructure is directly proportional to train velocity. Then the deformation decrease with speed 


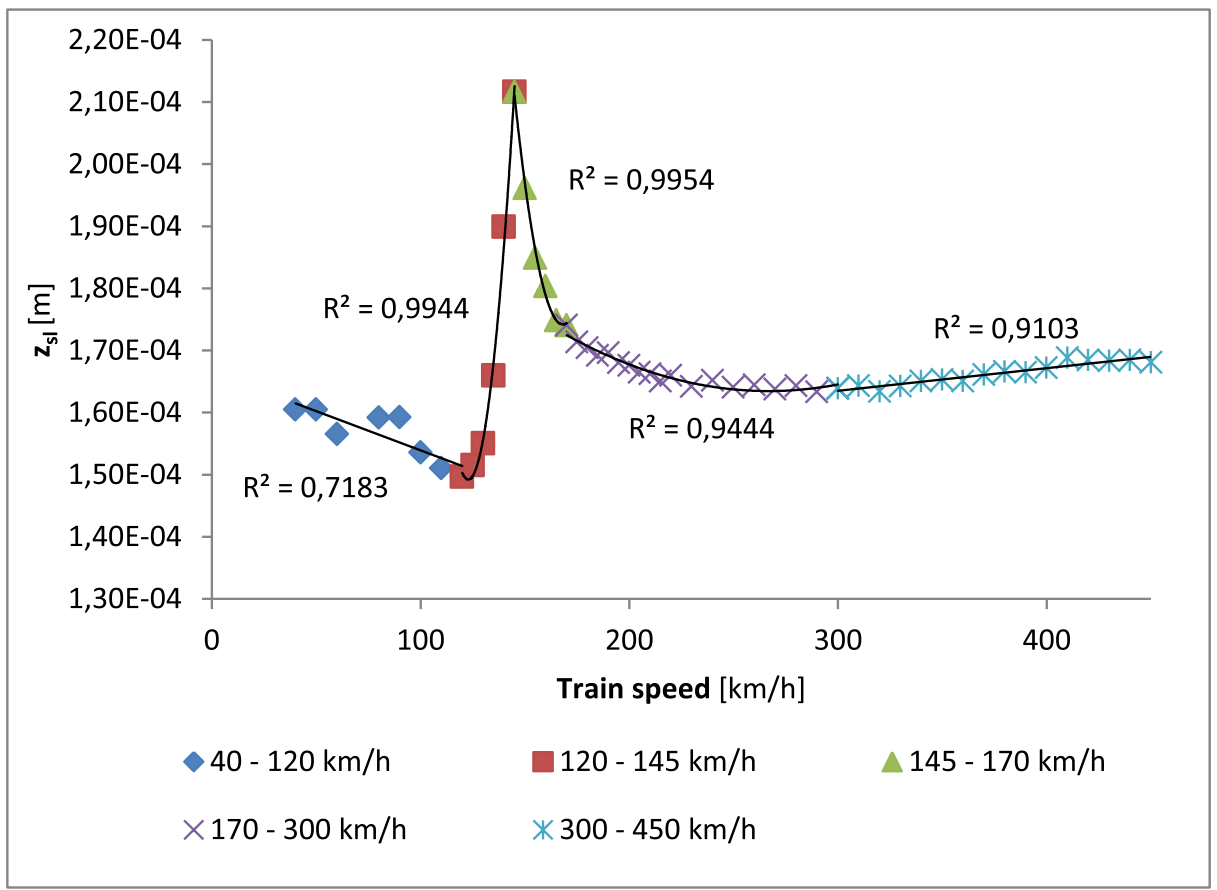

(a)

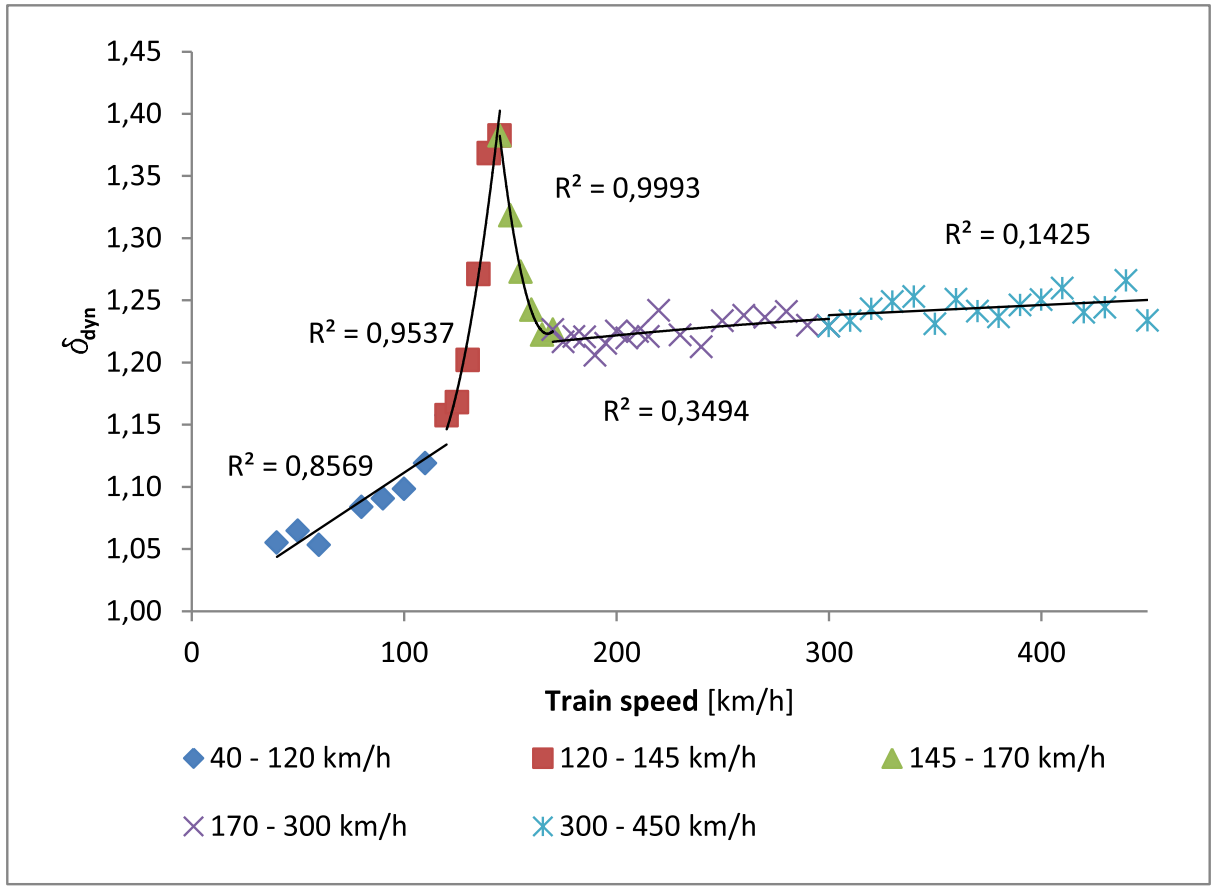

(b)

Figure 3: Scenario 2 (a) Sleeper vertical displacement and (b) dynamic amplification factor in function of train speed

increasing. In the second range $120-145 \mathrm{~km} \mathrm{~h}^{-1}$ the behavior changes totally. In this interval the elastic deflection increases quickly up to a critical speed 
( $145 \mathrm{~km} \mathrm{~h}^{-1}$ in this case). Once the critical speed is passed the elastic deflection decreases quickly in the range $145-170 \mathrm{~km} \mathrm{~h}^{-1}$. This interval, where the deflection increases and decreases quickly, is centered on critical speed with a range of $V_{c} \pm 25 \mathrm{~km} \mathrm{~h}^{-1}$. Once this interval is passed, the deflection continues to decrease but with a smaller slope. This range is $170-300 \mathrm{~km} \mathrm{~h}^{-1}$. Finally the deflection restarts to increase with a small inclination in the range $300-450 \mathrm{~km} \mathrm{~h}^{-1}$. Focusing on figure 3(b), the behavior of dynamic amplification factor has been divided in five range too, only to compare intervals with elastic deflection chart. In this case the dynamic amplification factor is proportional to speed in first, fourth and fifth interval. In the range $V_{c} \pm 25 \mathrm{~km} \mathrm{~h}^{-1}$, it assumes the same behavior than sleeper deflection. Some guesswork could be done comparing curves. Overlooking what happens near to the critical speed, the elastic deflection must obey to two physical phenomenons contemporaneously. The first one is about the equivalent complex modulus of substructure. It could be deduced, force being equal, that the elastic deflection should always decrease with speed increasing. The second phenomenon can be seen focusing on dynamic amplification factor behavior. Indeed, increasing the speed, the dynamic load increases too. It follows that the elastic deflection should increase with the dynamic load increasing. Finally these two phenomenons contrast each to other. In the second scenario, the first phenomenon wins on second one up to $300 \mathrm{~km} \mathrm{~h}^{-1}$ speed. Once this speed is passed the dynamic loads still increases inversing the process. 


\section{The receptance analysis}

A numerical receptance analysis has been carried out to locate the resonance frequencies of the vehicle/track coupling system. Focusing on the track behavior, when any vehicle is present, the natural frequencies of the substructure have been abundantly studied in literature [20] and a resonance effect has been found at the so-called pinned-pinned frequency (about $800-1000 \mathrm{~Hz}$ ). Actually, the vehicle presence plays an important role on the system normal modes of vibrating. The vehicle masses (the wheels mass mainly) delay the system vibrations causing a reduction of the resonance frequency. For this reason, when two different trains are coupled to the track systems, the behavior of the vehicle/track coupling system changes clearly. To study the natural frequencies of the system, the third wheel of the vehicle model has been placed at the center of track. Both midspan excitation and on-sleeper excitation have been tested to analyze the receptance. A draft of these combinations is shown in Figure 4. The impulsive force has been applied at the same position of the contact force.

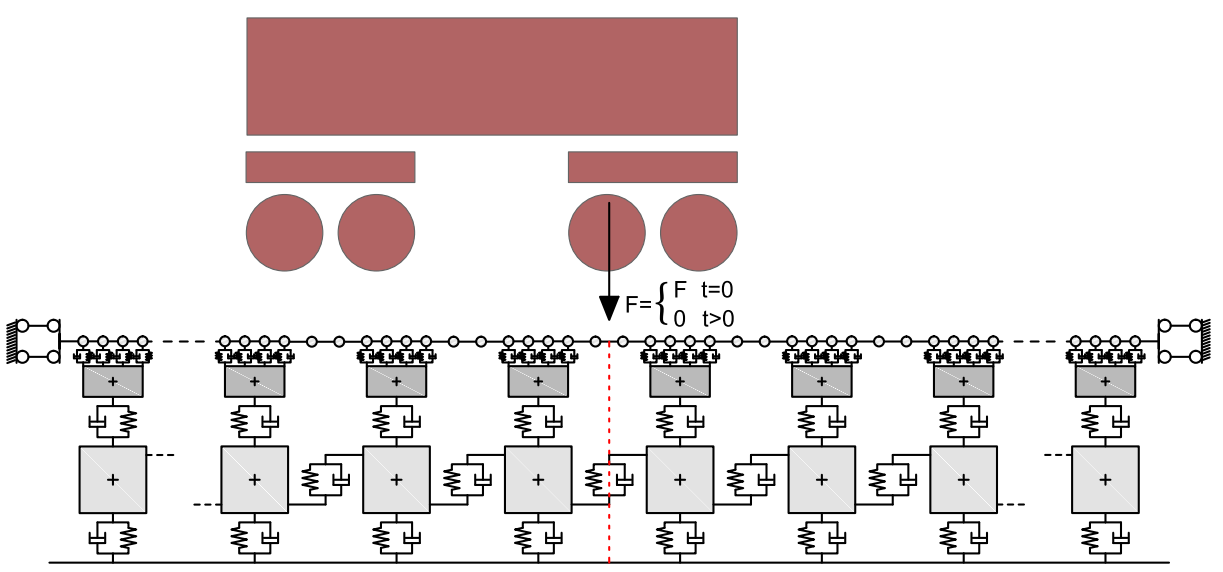

(a)

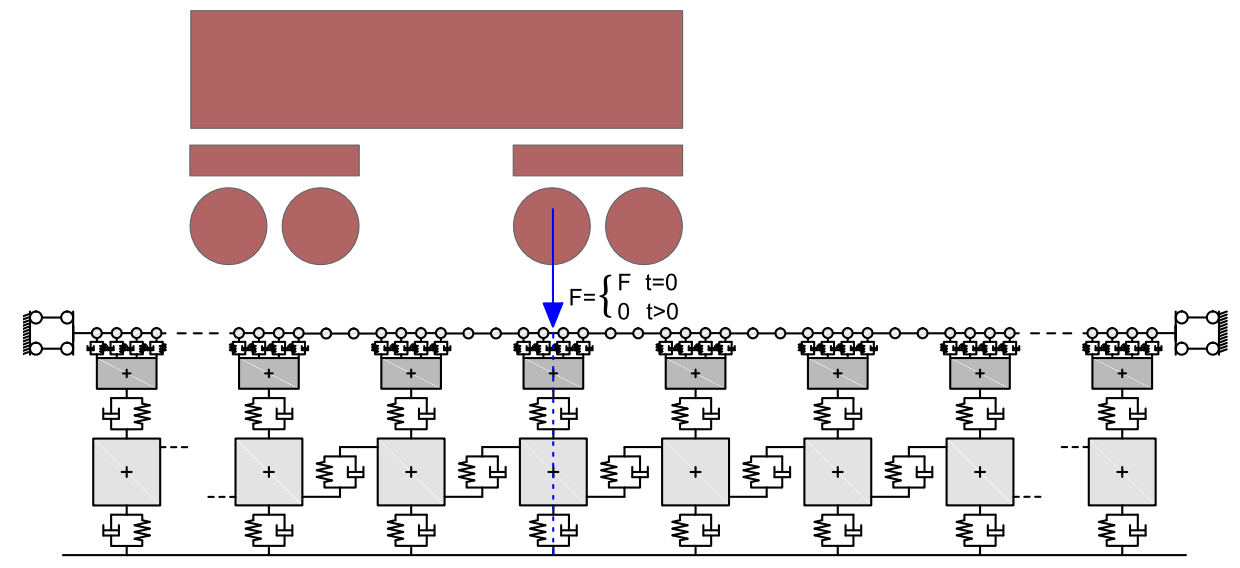

(b)

Figure 4: Type of excitation for the receptance simulation: (a) centered third wheel, midspan excitation; (b) centered third wheel, on-sleeper excitation. 
The results are totally different if compared to ones without the train. As shown in paragraphs 4.1 and 4.2 , the receptance reveals one singular peak in a low frequency range $50-120 \mathrm{~Hz}$ (see Figures 7, 9). An example of the wave propagation in time and space is shown in Figure 5. The results of the two scenarios are presented in the following paragraphs.

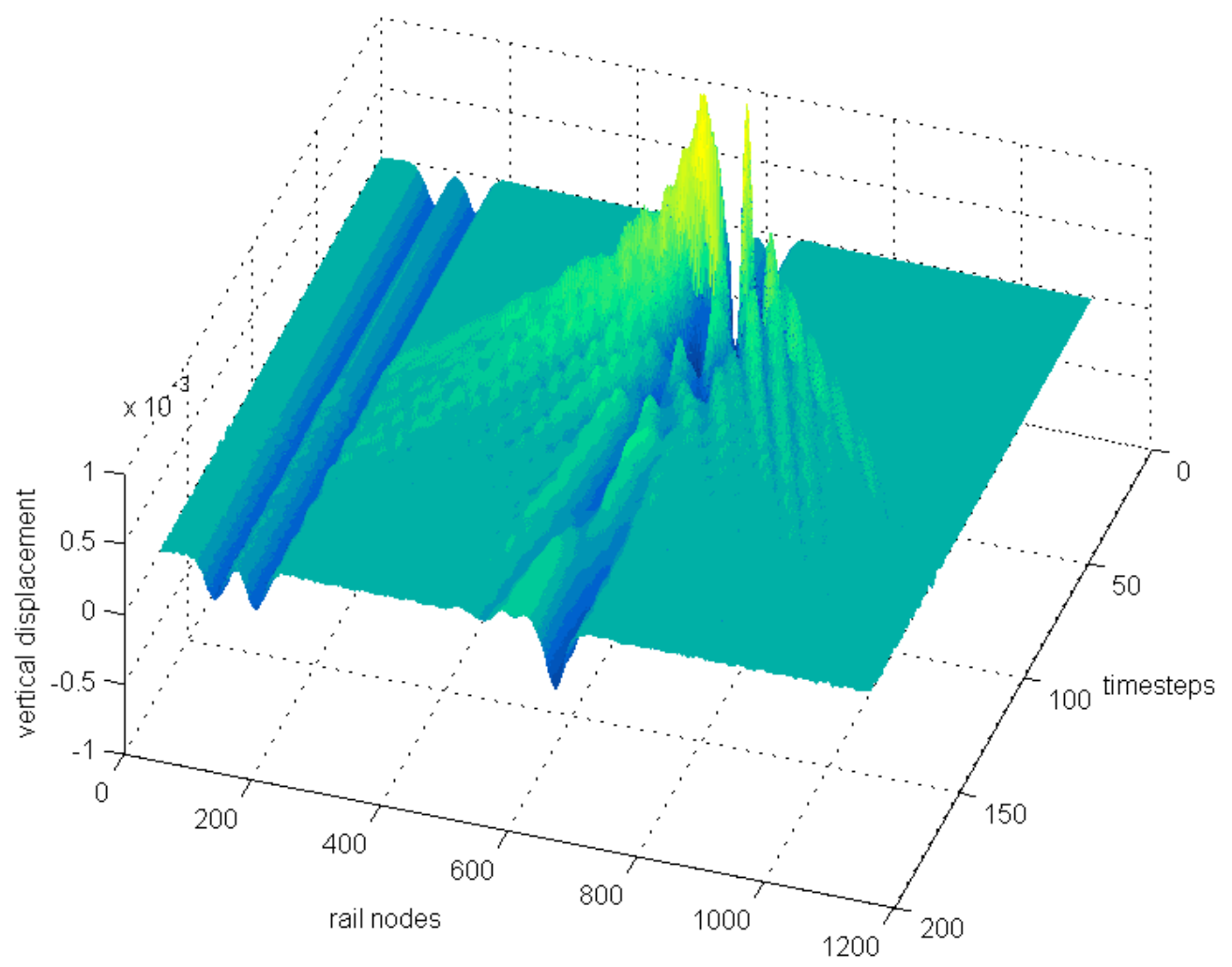

Figure 5: Waves propagation in time and in space in the case of centered third wheel, on-sleeper excitation.

\subsection{Scenario 1}

The vertical displacement of the excited point is shown in Figure 6 and the receptance analysis are shown in Figure 7. Carrying out the analysis in the cases of midspan excitation and on-sleeper excitation (Figure 4), we have noticed that the normal modes are the same, therefore, the following considerations are valid in both cases. Looking at Figure 7(a) a resonance frequency can be recognized at about $108.4 \mathrm{~Hz}$. Other natural frequencies, some of ones with a very smaller amplitude, may be recognized at about 90, 200 and 300 Hz. In Figure 6 the vertical displacement of the excited point is shown in function of time steps; focusing on it, it can be seen how, after few time-steps (red dotted line), all frequencies have been damped except the one at $104.8 \mathrm{~Hz}$. This fact is confirmed in Figure 7(b) where the FFT algorithm has been applied only in the part of function after the red dotted line, indeed, in this case, a clear peak is present at the frequency 


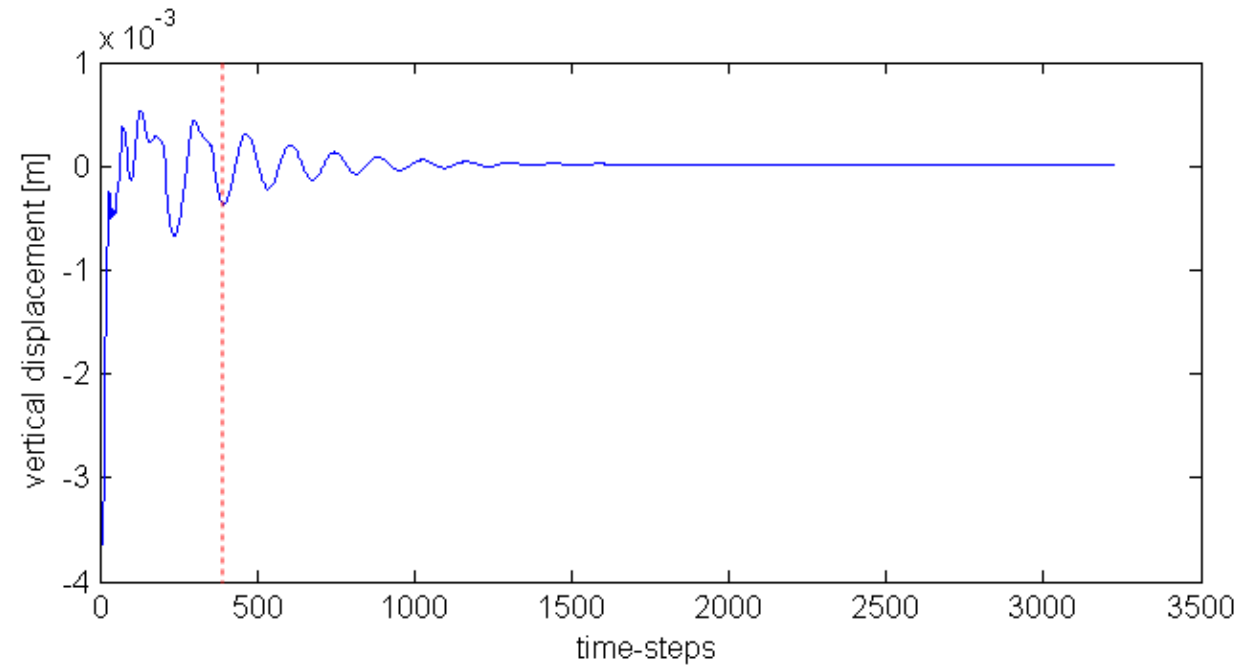

Figure 6: Vertical displacement for the receptance analysis in the scenario 1.

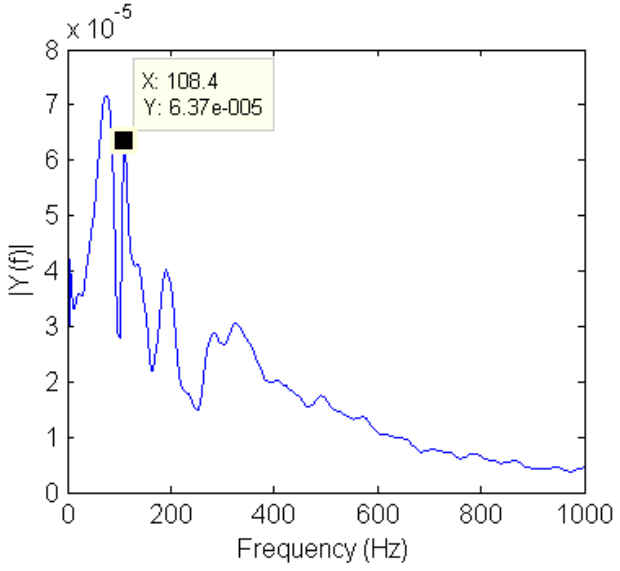

(a)

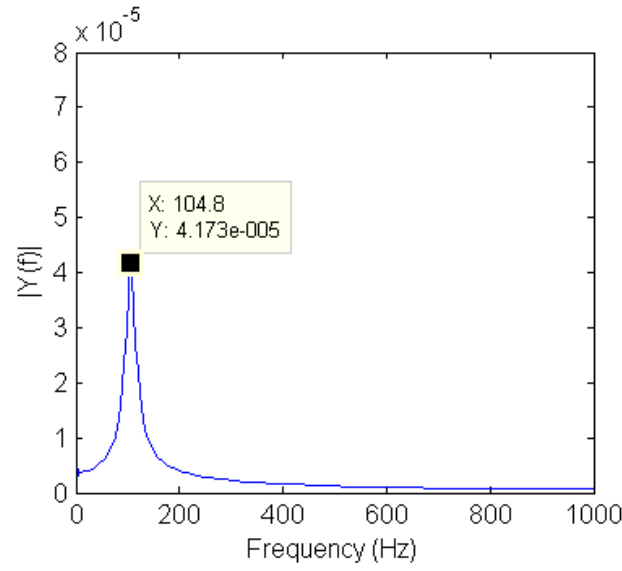

(b)

Figure 7: Comparison between: (a) the receptance considering all time-steps and (b) the receptance considering stabilized part in the scenario 1 .

\subsection{Scenario 2}

The vertical displacement of the excited point is shown in Figure 8 and the receptance analysis are shown in Figure 9. Even in this scenario a receptance analysis of the vertical displacement after the cut-off of the higher frequency is shown in Figure 9(b). 


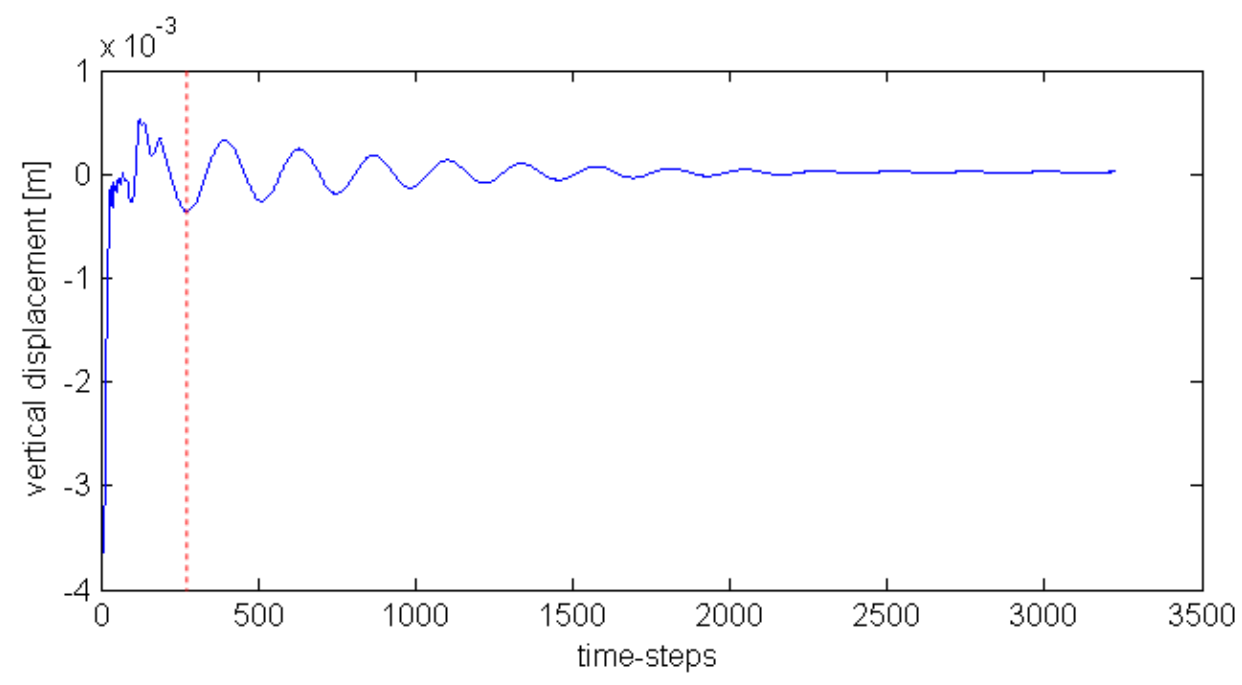

Figure 8: Vertical displacement for the receptance analysis in the scenario 2.

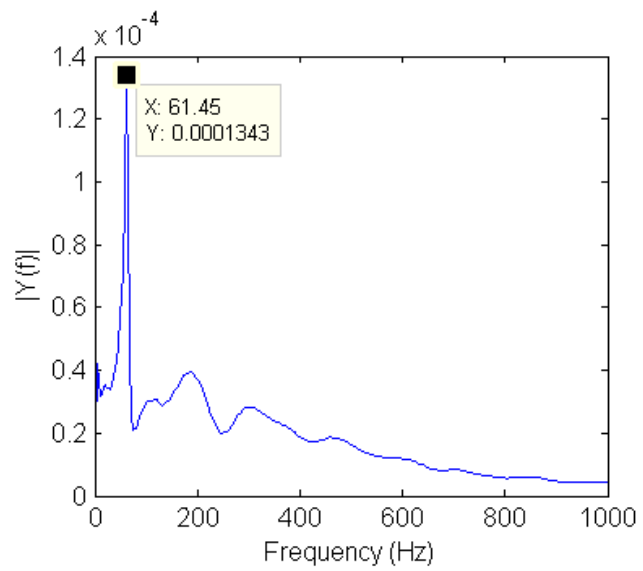

(a)

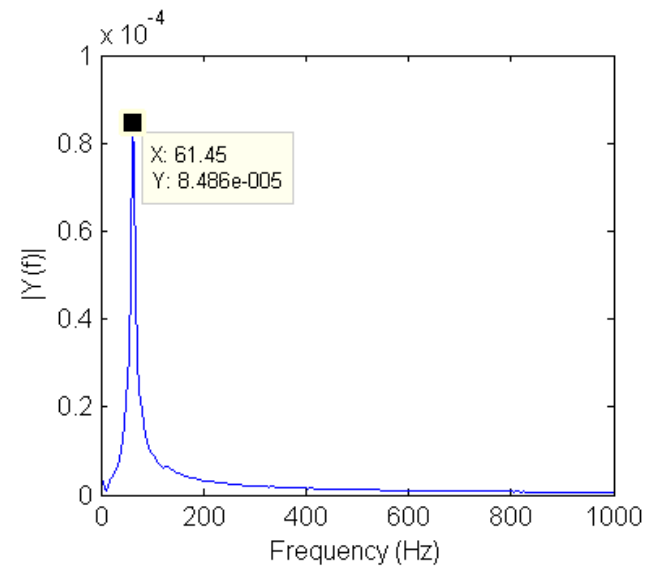

(b)

Figure 9: Comparison between: (a) the receptance considering all time-steps and (b) the receptance considering stabilized part in the scenario 2 .

\section{A new explanation of the critical speed}

The major source of excitation of the contact force is the so-called sleeper passing frequency. In both cases shown in last paragraph the sleeper base adopted is $65 \mathrm{~cm}$. Considering this length as the wavelength of the excitation function it can be convenient to compare resonance frequencies and speed with the relationship:

$$
V=3.6 \cdot 0.65 \cdot f \quad\left[k m h^{-1}\right],
$$

being $f$ the frequencies expressed in $\mathrm{Hz}$. This relation 1 connects the velocity of the wheel $j$ with the sleeper passing frequency. Many authors have compared 
the natural frequencies determined by the analysis of receptance of the track system with the train speed. Anyway, as explained in paragraph 4, train masses and suspension play an important role during the contact with track, modifying its response. Then, it results necessary to compare speeds with receptance analysis of the coupling structure considering both systems: train and substructure. The comparison between receptances of coupled system and the vertical sleeper displacement in function of speed are shown in figures 10 and 11. A surprising results has emerged. The perfect coincidence between critical speed and resonance frequency of the coupled system is shown. It follows that a critical speed cannot be connected uniquely to substructure properties but it is necessary to considerate always the coupled system.

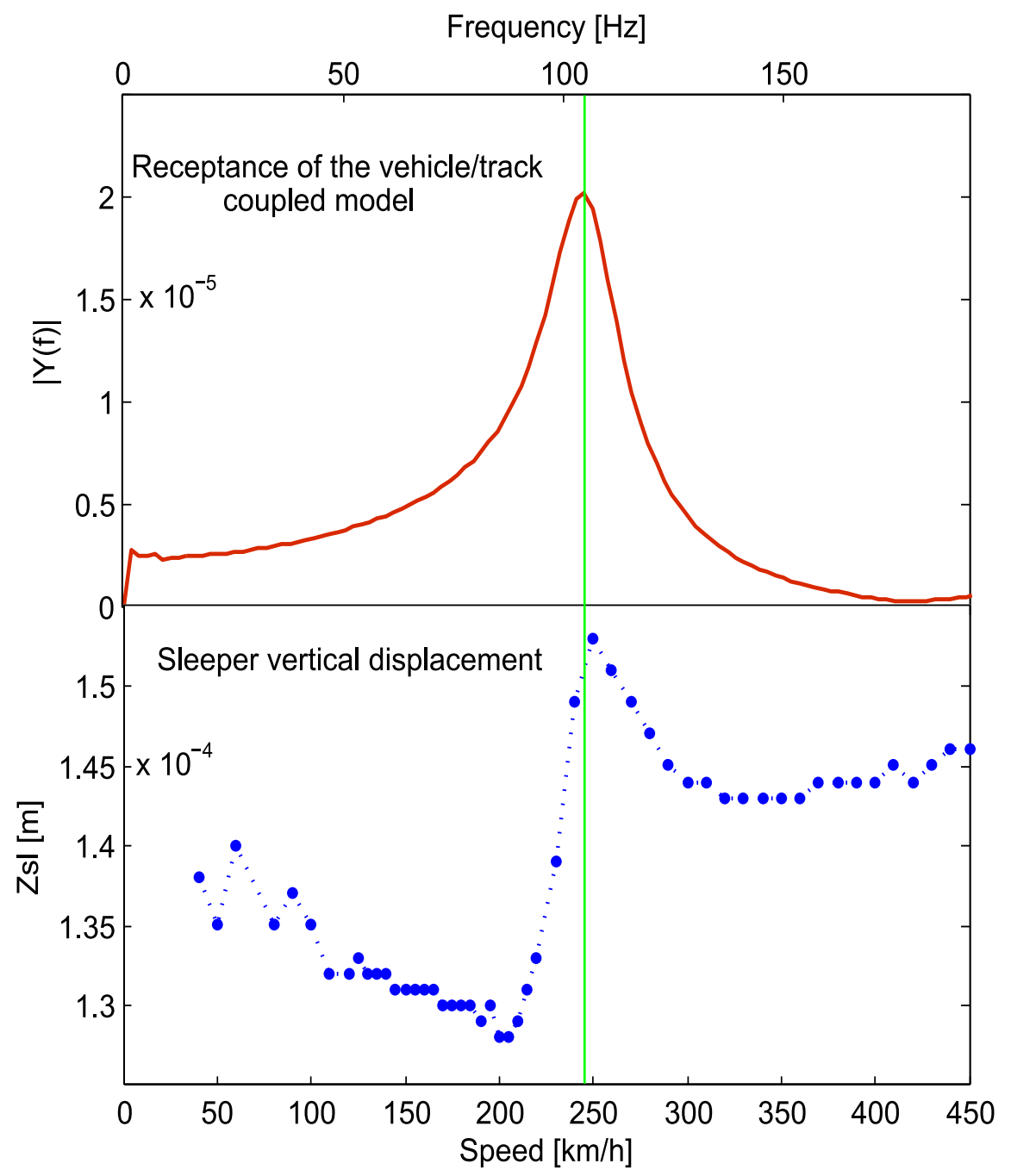

Figure 10: Scenario 3: comparison between critical speed and resonance frequency 


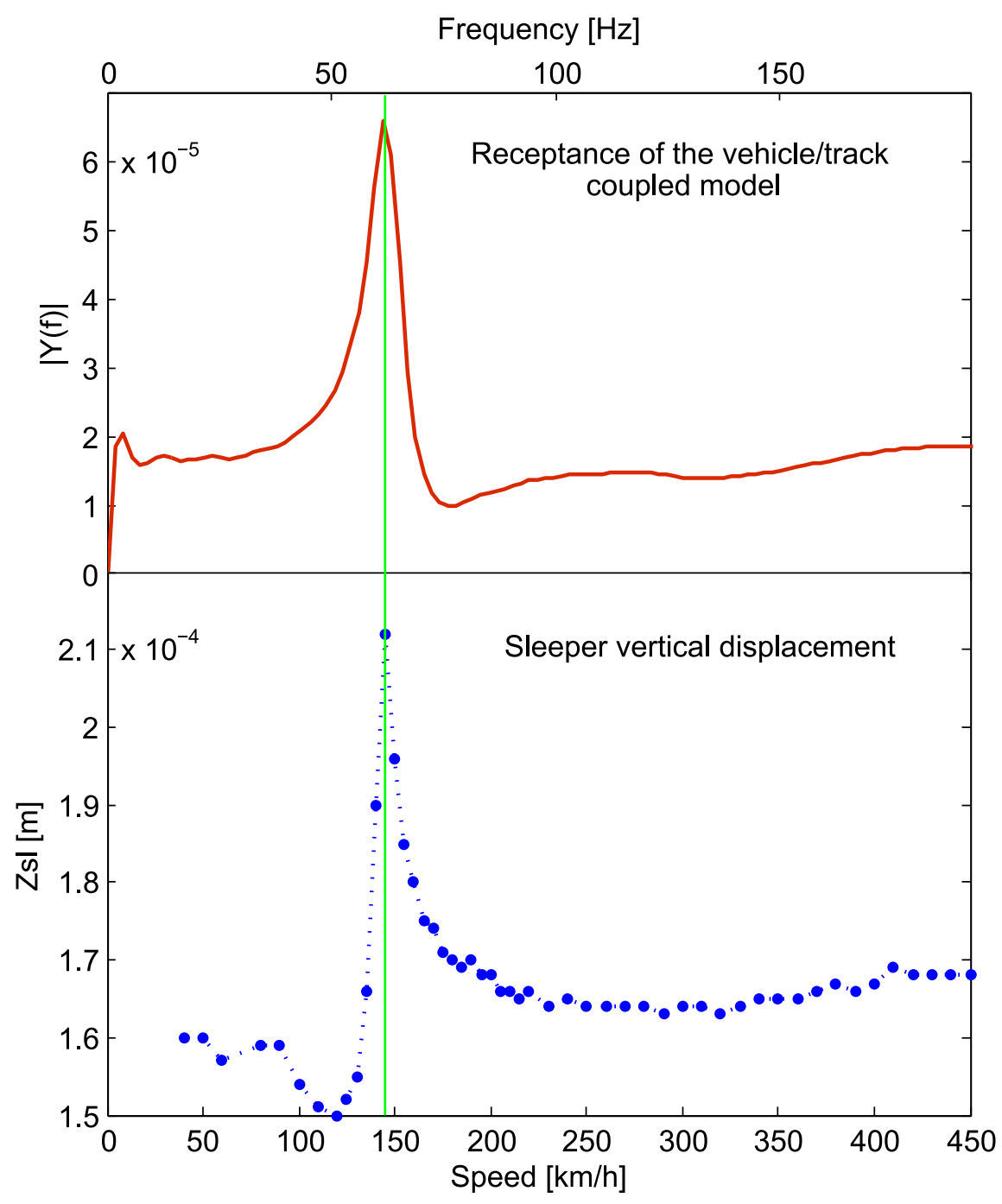

Figure 11: Scenario 4: comparison between critical speed and resonance frequency

\section{Conclusion and perspective}

This work shows an evident relationship between the receptance of the train/track coupling system and the so called sleeper-passing frequency. The amplification of vibrations happens when the train speed causes the equivalence between the sleeper-passing frequency and the receptance of the train/track coupling system. This explanation seems to be definitively complete even if only a numeric validation is presented in the thesis, however the results look extremely promising. As perspective the results of numerical simulation may be compared to experimental data. 


\section{References}

[1] M. Sunaga, E. Sekine, T. Ito, "Vibration behaviors of roadbed on soft grounds under train load", Quart Rep Railway Tech Res Inst, 31(1): 29 35, 1990.

[2] V.V. Krylov, "Generation of ground vibrations by superfast trains", Applied Acoustics, 44(2): 149 - 164, 1995, ISSN 0003-682X.

[3] A. Wolfert, H. Dieterman, A. Metrikine, "Passing through the "elastic wave barrier" by a load moving along a waveguide", Journal of Sound and Vibration, 203(4): 597 - 606, 1997, ISSN 0022-460X.

[4] D.H. A., M.A. V., "Steady-state displacements of a beam on an elastic half-space due to a uniformly moving constant load", European journal of mechanics. A. Solids, 16(2): 295 - 306, 1997, ISSN 0997-7538.

[5] C. Madshus, A. Kaynia, "High-speed railway lines on soft ground: dynamic behaviour at critical train speed", Journal of Sound and Vibration, 231(3): 689 - 701, 2000, ISSN 0022-460X.

[6] K. V.V., "Effects of Track Properties on Ground Vibrations Generated by High-Speed Trains", Acta Acustica united with Acustica, 84(1): 78 - 90, 1998.

[7] K. V.V., "Ground vibration boom from high-speed trains: prediction and reality", Acoustics Bulletin, 23(4): 15 - 22, 1998.

[8] M. Lieb, B. Sudret, "A fast algorithm for soil dynamics calculation by wavelet decomposition", Archive of Applied Mechanics, 68: 147 - 157, 1998.

[9] C. Esveld, A. Kok, "Post-Doctoral Course on High Speed Track", 1997, Technische Universitet Delf.

[10] R. Ferrara, G. Leonardi, F. Jourdan, "Numerical Modelling of Train Induced Vibrations", Procedia - Social and Behavioral Sciences, 53(0): 155 - 165, 2012, ISSN 1877-0428, SIIV-5th International Congress - Sustainability of Road Infrastructures 2012.

[11] R. Ferrara, G. Leonardi, F. Jourdan, "A contact-area model for rail-pads connections in 2-D simulations: sensitivity analysis of train induced vibrations", Vehicle System Dynamics, 2013, in press.

[12] R. Ferrara, A numerical model to predict train induced vibrations and dynamic overloads, $\mathrm{PhD}$ thesis, University of Reggio Calabria - Department of Civil, Energy, Environment, Materials Engineering (DICAM) in joint supervision with University of Montpellier 2 - Mechanical and Civil Engineering Laboratory (LMGC)", 2013. 
[13] W. Zhai, Z. Cai, "Dynamic interaction between a lumped mass vehicle and a discretely supported continuous rail track", Computers \& Structures, 63 (5): 987 - 997, 1997, ISSN 0045-7949.

[14] G. Di Mino, C. Di Liberto, J. Nigrelli, "A FEM model of rail trackground system to calculate the ground borne vibrations: a case of rail track with wooden sleepers and k-fastenings at Castelvetrano", in Proceeding of Advanced Characterisation of Pavement and Soil Engineering Materials. Athens, Greece, 2007.

[15] Y.Q. Sun, M. Dhanasekar, "A dynamic model for the vertical interaction of the rail track and wagon system", International Journal of Solids and Structures, 39(5): 1337 - 1359, 2002, ISSN 0020-7683.

[16] J. Zhang, Q. Gao, S. Tan, W. Zhong, "A precise integration method for solving coupled vehicletrack dynamics with nonlinear wheelrail contact", Journal of Sound and Vibration, 331(21): 4763 - 4773, 2012, ISSN 0022$460 X$.

[17] X. Lei, N.A. Noda, "Analyses of dynamic response of vehicle and track coupling system with random irregularity of track vertical profile", Journal of Sound and Vibration, 258(1): 147 - 165, 2002, ISSN 0022-460X.

[18] W. Zhai, K. Wang, J. Lin, "Modelling and experiment of railway ballast vibrations", Journal of Sound and Vibration, 270(4-5): 673 - 683, 2004, ISSN 0022-460X.

[19] S. Iwnick, "Manchester Benchmarks for Rail Vehicle Simulation", Vehicle System Dynamics, 30(3-4): 295-313, 1998.

[20] K. Knothe, S. Grassie, "Modelling of Railway Track and Vehicle/Track Interaction at High Frequencies", Vehicle System Dynamics, 22(3-4): 209$262,1993$.

\section{Annex A}

\section{A.1 - Definition of the sleeper vertical deflection and the dynamic amplification factor}

The output parameters selected for the analysis are the sleeper elastic vertical deflection $z_{s l}$ and the dynamic amplification factor of the wheel-rail contact force $\delta_{\text {dyn }}=R_{w / r} / R_{\text {static }}\left(R_{\text {static }}\right.$ is the vehicle weight divided by the number of wheels). The sleeper chosen to check the maximum deflection value is the nearest one to the midpoint between the end of the railway length and the fourth wheel from the left. Among others, this sleeper is the one less affected by boundary effects. The dynamic amplification factor is time dependent. The contact force $R_{w / r}$ varies around the static value during the simulation and at certain time step it assumes very high values. Anyway, these values are singular points and 
do not represent the complete behavior of contact-force during the whole time of simulation $T$. The following procedure has been conducted to choose a representative output parameter. The time interval $[0, T]$ has been divided in $p$ intervals of size $\tau$. For each $g$-range the maximum value of the dynamic amplification factor $\delta_{d y n, g}$ has been evaluated for the third wheel from the left. In fact, the third wheel is the one less affected by boundary effects. Therefore the average between maximum values in all the time ranges has been calculated for each simulation. The procedure is summarized in equation (2).

$$
\left\{\begin{array}{l}
\overline{\delta_{d y n}}=\sum_{g=1}^{p} \frac{\delta_{d y n, g}}{p} \\
p=\frac{T}{\tau} \\
\delta_{\text {dyn, }, g}=\max \left[\frac{R_{w / r, 3}(t)}{R_{\text {static }}}\right] \quad t \in[(g-1) \tau,(g) \tau] ; g=1,2, \ldots, p
\end{array}\right.
$$

The interval $\tau$ has been calculated as the time necessary to cover the passing of three consecutive sleepers. The sleeper distance used is 0.65 meters, so $\tau$ has been calculated as $2.3 \mathrm{~m} / V$, being $(3 \times 0.65 \mathrm{~m})<2.3 \mathrm{~m}$. An example for $p=3$ is shown in figure 12 .

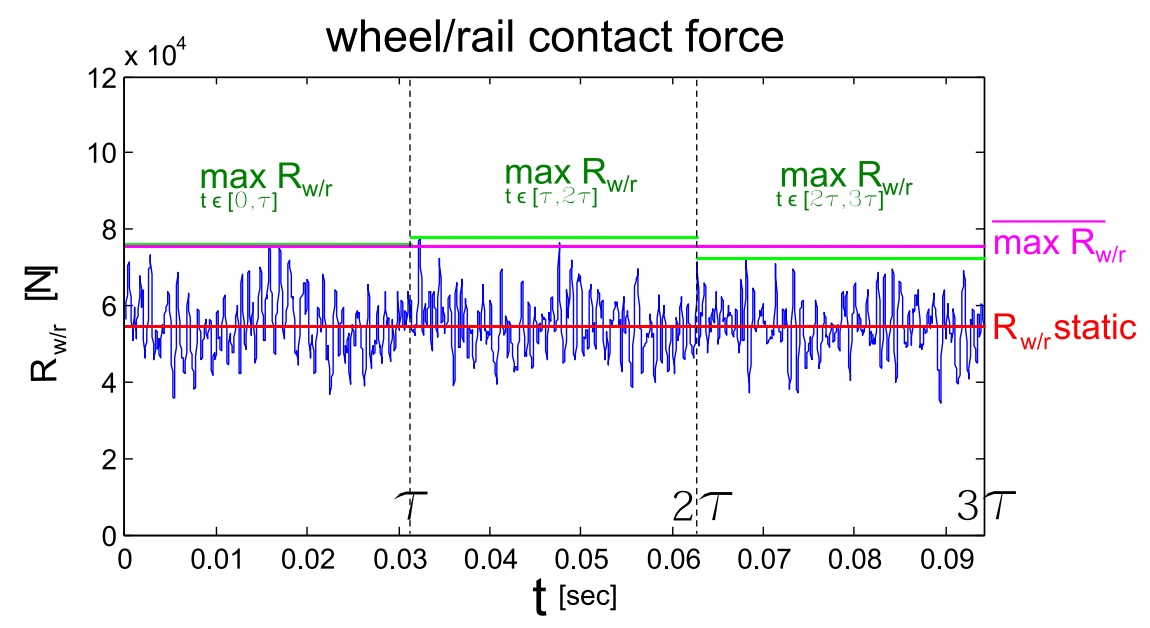

Figure 12: An example for the determination of the average dynamic amplification factor. 


\section{A.2 - Model parameters adopted in the Scenario 1}

Table 1: Model parameters adopted for the simulation in the first scenario. Scenario 1

\begin{tabular}{|c|c|c|c|}
\hline notation & parameter & value & unit \\
\hline & Model parameters of substructure ${ }^{a}$ & & \\
\hline$E$ & young modulus of rail & $2.07 \cdot 10^{11}$ & $\mathrm{Nm}^{-1}$ \\
\hline$I$ & inertial modulus of rail & $3038.3 \cdot 10^{-8}$ & $\mathrm{~m}^{4}$ \\
\hline$A$ & section area of rail & $76.70 \cdot 10^{-4}$ & $\mathrm{~m}^{2}$ \\
\hline$\chi$ & Timoshenko shear coefficient & 0.34 & \\
\hline$m_{r}$ & railway mass (per unit length) & 60.21 & $\mathrm{~kg} \mathrm{~m}^{-1}$ \\
\hline$M_{s}$ & sleeper mass & 125 & $\mathrm{~kg}$ \\
\hline$M_{b}$ & ballast mass & 500 & $\mathrm{~kg}$ \\
\hline$k_{p}$ & pad stiffness & $1.70 \cdot 10^{8}$ & $\mathrm{Nm}^{-1}$ \\
\hline$c_{p}$ & pad damping & $3.00 \cdot 10^{4}$ & $\mathrm{Ns} \mathrm{m}^{-1}$ \\
\hline$k_{b}$ & ballast stiffness & $2.00 \cdot 10^{8}$ & $\mathrm{~N} \mathrm{~m}^{-1}$ \\
\hline$c_{b}$ & ballast damping & $8.50 \cdot 10^{4}$ & $\mathrm{Ns} \mathrm{m}^{-1}$ \\
\hline$k_{f}$ & subgrade stiffness & $1.50 \cdot 10^{9}$ & $\mathrm{~N} \mathrm{~m}^{-1}$ \\
\hline$c_{f}$ & subgrade damping & $5.00 \cdot 10^{4}$ & $\mathrm{~N} \mathrm{~s} \mathrm{~m}^{-1}$ \\
\hline \multirow[t]{2}{*}{$l_{s}$} & sleeper base & 65 & $\mathrm{~cm}$ \\
\hline & Model parameters of train $A \ln 668^{b}$ & & \\
\hline $2 M_{c}$ & car body mass & 28800 & $\mathrm{~kg}$ \\
\hline$M_{b}$ & bogie mass & 3600 & $\mathrm{~kg}$ \\
\hline $2 M_{w}$ & wheelset mass & 500 & $\mathrm{~kg}$ \\
\hline$l_{c}$ & total length & 23540 & $\mathrm{~mm}$ \\
\hline $2 l_{b}$ & wheelset base & 2.45 & $\mathrm{~m}$ \\
\hline $2 l_{w}$ & bogie base & 15.95 & $\mathrm{~m}$ \\
\hline$k_{1}$ & primary suspension stiffness & 500 & $\mathrm{kN} \mathrm{m}^{-1}$ \\
\hline$k_{2}$ & secondary suspension stiffness & 8800 & $\mathrm{kN} \mathrm{m}^{-1}$ \\
\hline$c_{1}$ & primary suspension damping & 0.5 & $\mathrm{kN} \mathrm{s} \mathrm{m}^{-1}$ \\
\hline \multirow[t]{2}{*}{$c_{2}$} & secondary suspension damping & 41.5 & $\mathrm{kN} \mathrm{s} \mathrm{m}^{-1}$ \\
\hline & Other simulation parameters & & \\
\hline$d t$ & time step & $6 \cdot 10^{-5}$ & $\mathrm{~S}$ \\
\hline$K_{h}$ & Hertz contact coefficient ${ }^{a}$ & $0.87 \cdot 10^{11}$ & $\mathrm{~N} \mathrm{~m}^{-3 / 2}$ \\
\hline$L_{s}$ & simulation line length & 64.45 & $\mathrm{~m}$ \\
\hline
\end{tabular}

${ }^{a}$ parameters extracted from [12].

${ }^{b}$ parameters extracted from [14]. 